\title{
EST ÁGIOS IMATUROS DE PLATYPHORA ZONATA (GERMAR, 1824) (COLEOPTERA, CHRYSOMELIDAE, CHRYSOMELINAE)
}

\author{
Nelson Bernardi ${ }^{1}$ \\ Adelmo Scivittaro ${ }^{1}$
}

\begin{abstract}
The immature stages of Platyphora zonata (Germar, 1824) are described, with comments on habits.

O presente trabalho descreve as características morfológicas externas principais dos estágios imaturos de Platyphora żonata (Germar, 1824), fornecendo também algumas informações acerca dos hábitos.

O material foi identificado por comparações com exemplares do Museu de Zoologia da Universidade de São Paulo identificados por J. Bechyné.

Todo o material estudado provém do município de Botucatu, São Paulo. Os vários estágios, três. larvas, pupas e adultos, foram sempre observados e capturados sobre folhas de Solanum lycocarpum (Solanaceae), planta conhecida como "fruta-de-lobo". Examinamos grande número de exemplares de todos os estágios. Boa parte do material foi criada em laboratório, em víveiros, sobre a planta hospedeira.

A fêmea é larvípara, podendo fazer mais de uma postura com intervalo de alguns dias, eliminando de vinte a trinta larvas por postura. As larvas do primeiro estágio ficam geralmente imóveis e agrupadas (Fig. 1) por um ou dois dias, antes de alimentarem-se.

Larvas e adultos alimentam-se das folhas diferentemente. As larvas comem a epiderme e o parênquima, deixando apenas o retículo formado pelas nervuras (Fig. 3). Os adultos comem pelos bordos da folha, ingerindo material de toda a espessura. Os detritos provenientes da alimentação das larvas de primeiro e segundo estágios ficam aderidos à pilosidade do abdome (Fig. 2).

Em todos os estágios, as larvas são gregárias.

A seguir, descrevemos e ilustramos as larvas do terceiro estágio (Figs. 4-9) e a pupa (Fig. 12). As larvas de primeiro (Fig. 10) e segundo (Fig. 11) estágios são apenas ilustrados. Em nossa descrição, procuramos acompanhar, na medida do possível, a descrição de Calligrapha polyspila Germar, 1821, espécie da mesma subfamília, divulgada por COSTA, VANIN \& CASARI-CHEN (1988).

Larva madura. Comprimento: $11.12 \mathrm{~mm}$. Cifossomática. Tórax castanho, com a região dorsal do mesotórax mais escura que o protórax e dorso do metatórax negro. Abdome negro, mas castanho escuro nos últimos segmentos. Pilosidade clara, rara e esparsa, um pouco mais longa e densa na cabeça e no fim do abdome. Integumento aveludado. Cabeça hipognata, fortemente esclerosada. Sutura coronal longa, atingindo o clípeo, ramos frontais ausentes. Seis estemas de cada lado, atrás da antena, quatro acima
\end{abstract}

1. Departamento de Zoologia, Instituto de Biociências, Universidade Estadual Paulista, 18610 Botucatu, São Paulo. 
Revta bras. Zool.
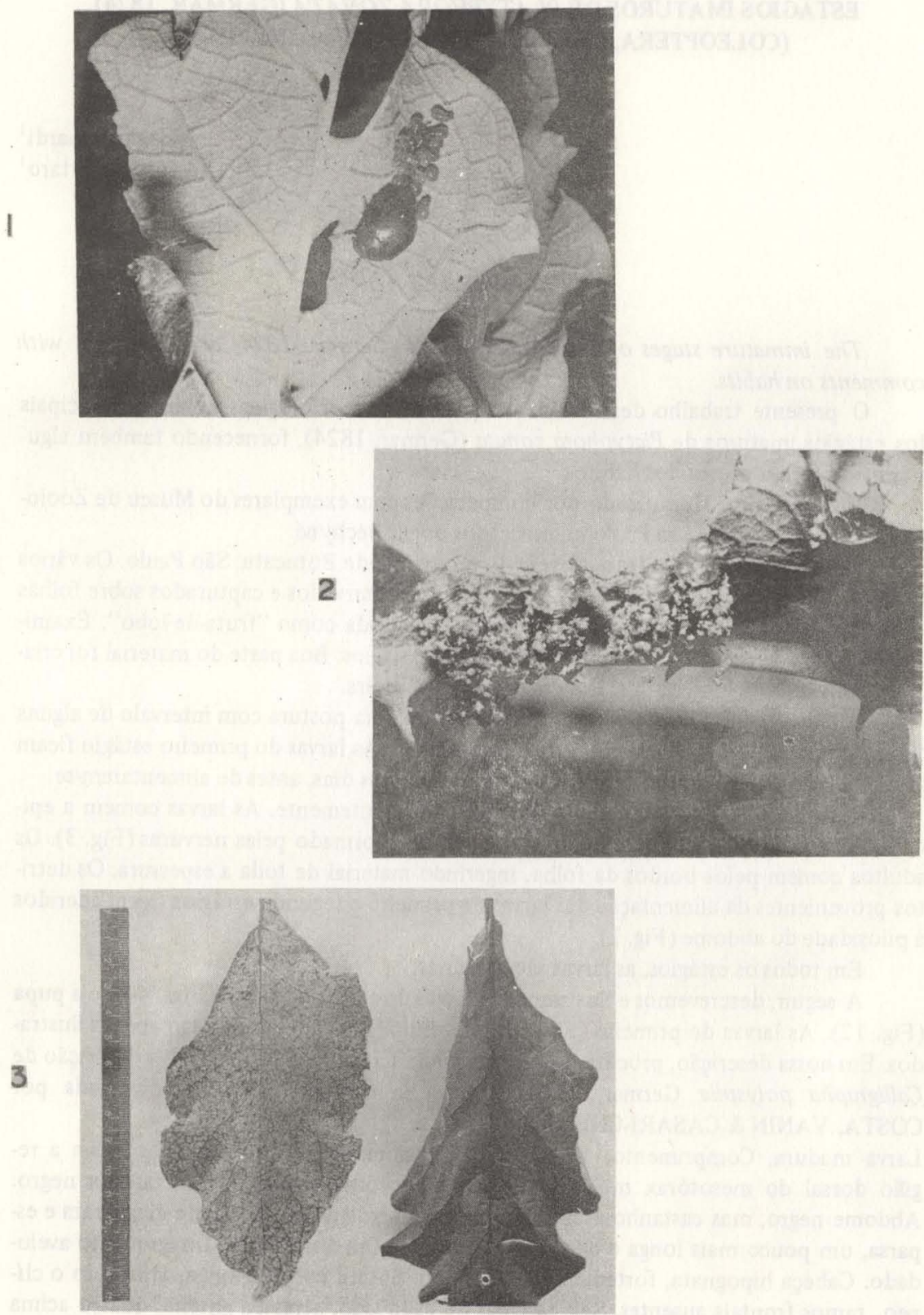

Figuras: 1. Fêmea e larvas de $1^{\circ}$. estágio recém-nascidas; 2 . Larvas de 20 estágio. Observar detritos aderidos à pilosidade abdominal; 3. Folhas antes e após a alimentação das larvas. 


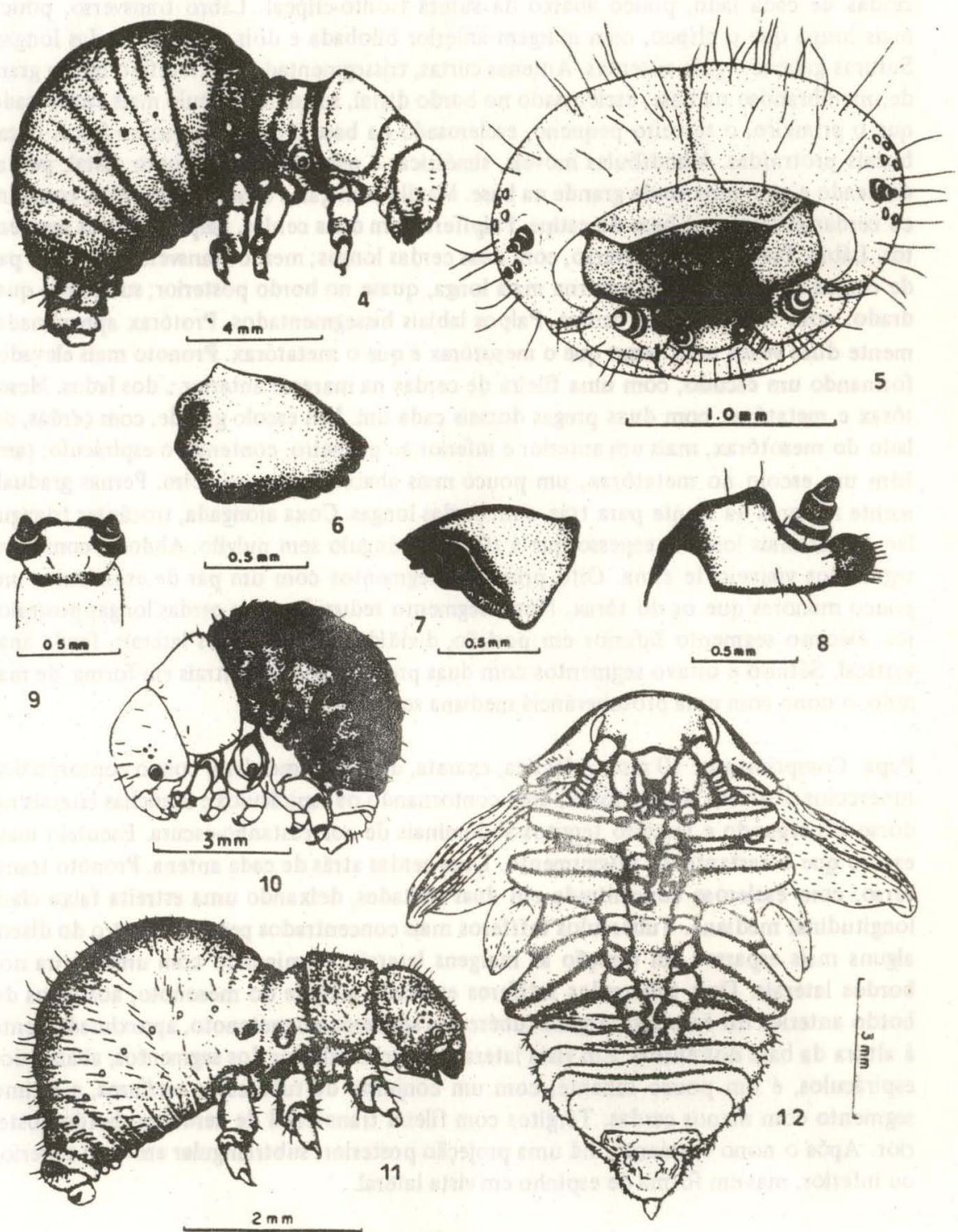

Figures: 4-9. Larva de 30 estágio; 4. Larva inteira; 5 . cabeça, de frente; 6 . Mand îbula esquerda, face externa; 7. Idem, face interna; 8 . Maxila direita, de frente; 9 . Lábio, de frente; 10. Larva de 10. estágio; 11 . Larva de 2 ? estágio; 12 . pupe. 
dela e dois abaixo. Sutura fronto-clipeal nítida. Clípeo transverso, subtrapezoidal, em forma de faixa estreita, bordo inferior arqueado em vista frontal, com um par de longas cerdas de cada lado, pouco abaixo da sutura fronto-clipeal. Labro transverso, pouco mais longo que o clípeo, com margem anterior bilobada e dois pares de cerdas longas. Suturas gulares e gula ausentes. Antenas curtas, trissegmentadas. Antenífero muito grande, membranoso na base, escle rosado no bordo distal, segundo artículo mais esclerosado que o primeiro, o terceiro pequeno, esclerosado na base e membranoso no ápice. Peças bucais protraídas. Mandíbulas móveis, simétricas e palmadas, com bordo distal, pentadenteado e com uma cerda grande na base. Maxila com gálea e lacínia fundidas, com cinco cerdas em linha na base do estipe. Palpífero com duas cerdas, palpo com três segmentos. Lábio. Pré-mento transverso, com duas cerdas longas; mento transverso, com um par de cerdas de cada lado, a externa mais longa, quase no bordo posterior; submento quadrado, com três pares de cerdas. Palpos labiais bissegmentados. Protórax aproximadamente duas vezes mais largo que o mesotórax e que o metatórax. Pronoto mais elevado, formando um escudo, com uma fileira de cerdas na margem anterior : dos lados. Mesotórax e metatórax com duas pregas dorsais cada um. Um escolo grande, com cerdas, do lado do mesotórax, mais um anterior e inferior ao primeiro, contendo o espiráculo; também um escolo no metatórax, um pouco mais abaixo que o primeiro. Pernas gradualmente maiores da frente para trás, com cerdas longas. Coxa alongada, trocânter triangular, fêmur mais longo e espesso que a tíbia, tarsíngulo sem pulvilo. Abdome com nove segmentos visíveis de cima. Oito primeiros segmentos com um par de espiráculos um pouco menores que os do tórax. Nono segmento reduzido, com cerdas longas posteriores. Décimo segmento inferior em posição, dividido em dois lobos laterais, fenda anal vertical. Sétimo e oitavo segmentos com duas protuberâncias ventrais em forma de mamilo, o nono com uma protuberância mediana semelhante.

Pupa. Comprimento: $10 \mathrm{~mm}$. Adéctica, exarata, de cor creme clara, com o contorno dos tubérculos setíferos do protórax, área contornando os espiráculos e manchas laterais no dorso do segundo e terceiro tergitos abdominais de cor castanhoescura. Escutelo mais escuro que o restante do integumento. Duas cerdas atrás de cada antena. Pronoto transverso, com esclerose concentrada em duas metades, deixando uma estreita faixa clara. longitudinal mediana. Tubérculos setíferos mais concentrados perto do centro do disco, alguns mais esparsos em direção às margens laterais, terminando com uma fileira nos bordos laterais. Dois tubérculos setíferos em cada metade do mesonoto, aos lados do bordo anterior do escutelo. Alguns tubérculos setíferos no metanoto, aproximadamente à altura da base dos élitros. Em vista lateral, a porção inferior dos segmentos, abaixo dos espiráculos, é um pouco saliente, com um conjunto de tubérculos setíferos, o sétimo segmento com menos cerdas. Tergitos com fileira transversal de cerdas no bordo posterior. Após o nono segmento, há uma projeção posterior, subtriangular em vista superior ou inferior, mas em forma de espinho em vista lateral.

\section{REFERENCIA}

COSTA, C., S.A. VANIN \& S.A. CASARI-CHEN, 1988. Larvas de Coleoptera do Brasil. Museu de Zoologia, Universidade de São Pulo, vii + 282 p., 165 estampas. 